\title{
Trend Analysis on Korean and International Management for Activated Material Waste from Medical Linear Accelerator
}

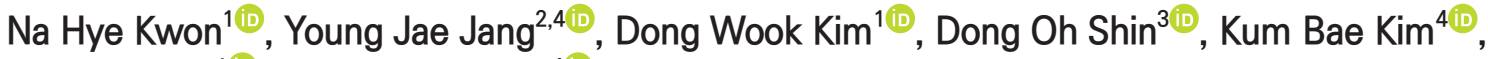 \\ Jin Sung Kim ${ }^{10}$, Sang Hyoun $\mathrm{Choi}^{4[1}$ \\ 'Department of Radiation Oncology, Yonsei Cancer Center, Yonsei University College of Medicine, Seoul, ${ }^{2}$ Department of Accelerator \\ Science, Korea University, Sejong, ${ }^{3}$ Department of Radiation Oncology, Kyung Hee University Hospital, ${ }^{4}$ Research Team of Radiological \\ Physics \& Engineering, Korea Institute of Radiological \& Medical Sciences, Seoul, Korea
}

Received December 22020 Revised December 92020

Accepted December 142020

\section{Corresponding author}

Sang Hyoun Choi

(sh524mc@gmail.com)

Tel: 82-2-970-1590

Fax: 82-2-970-2412
This study investigated and analyzed the Korean and international status of radioactive waste management for medical linear accelerators (linacs) and proceed prior research to suggest radiation safety regulations and guidelines for the safe use of radiation. We analyzed the number of linacs installed in the radiation oncology departments of 103 institutions. In addition, we analyzed the procedures and standards for disposal in Korea and foreign countries. For foreign countries, we analyzed the status based on reports from the United States, Japan, Europe, and Canada. A total of 182 linacs are installed in Korea and 95\% of them use more than 10 MV of energy. In Korea, standards for managing radioactive waste from a linac, disposal procedures, and clearance criteria have yet to be established. Therefore, radioactive waste is disposed of in different ways depending on the hospitals where they originate. Japan, the US, and Canada have recommended clearance levels and procedures for linacs. Other countries have provided management guidelines for research or large-scale accelerators, but not for medical purposes. In this study, we investigated the management of radioactive waste from medical linacs in Korea and abroad. Several foreign countries have suggested a clearance level and criteria for disposing of waste storage drums. For the safe management of medical linacs, it is necessary to establish safety management regulations. In Korea, standards for disposal, such as radiation or dose limits, are required for medical linacs. A system for clearance when disposing at a medical institution should be created.

Keywords: Linear accelerator, Disposal, Radioactive waste, Management, Clearance

\section{Introduction}

The radiotherapy device industry is growing as part of the development of radiotherapy technology. In particular, radiation treatment technology that uses high-energy radiation of 6 to $15 \mathrm{MV}$ or more is rapidly being incorporated by medical institutions; interest in the use of safe radiation therapy devices is also increasing while improving the quality of life of patients treated with high-precision radiation. Currently, most institutions in Korea and abroad use an 8-15 MV high-energy linear accelerator (linac), so using technology based on preceding radiation safety regulations is crucial. In Korea, however, it is difficult to systematically manage radioactive waste because of the absence of guidelines for disposal or replacement of linacs due to aging or failed parts. 
NCRP (National Council on Radiation Protection and Measurement) 79 and IAEA (International Atomic Energy Agency) TECDOC 1183 outlined the need to manage radioactive waste from internal components, such as a target, collimator, flattening filter, and ion chamber when dismantling a linac. The IAEA TECDOC 1183 showed that a possibility exists for the radiation of surrounding substances when using an accelerator of $10 \mathrm{MV}$ or more and that the head parts are activated during the disassembly of an linac; therefore, an evaluation of the activation should be conducted [1]. According to NCRP 79, when energy of 10 MV or more is used, a radiation evaluation is required and activation occurs in the head parts, such as the target, collimator, and flattening filter [2]. NCRP 151 states that when a high-energy accelerator of $10 \mathrm{MV}$ or more is used, radionuclides may be generated by the radiation of neutrons and gamma rays from the components of linac, which may result in exposure to patients and staff [3].

According to data from the Workshop for Improving Safety Management in the Medical Field, a total of 11 linacs were replaced from 2013 to 2017 and a total of 17 linacs were discarded [4]. On average, two or more linacs are replaced or discarded every year, although the relevant regulations and standards have yet to be established.

In accordance with the Nuclear Safety Commission Notice No. 2017-65, standards and clearance levels are stipulated according to the allowable concentration of nuclides [5]. However, information on radionuclides generated

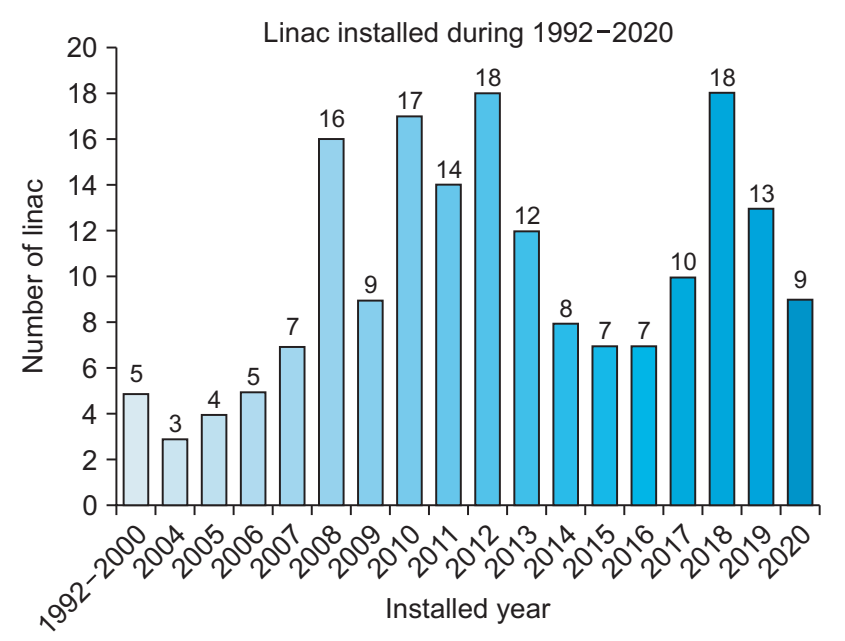

Fig. 1. Number of linear accelerators (linacs) installed domestically (1992-2020). during the process of discarding a linac is limited and variables, such as the number of patients, treatment methods, and treatment device models, change depending on the facility. Due to a lack of standardized regulations for disposal or management, an urgent need exists for the development of a management plan for the disposal of radioactive waste.

The operational period of a linac is typically 10 to 15 years and linacs are replaced or discarded for various reasons, such as aging parts, failure of major parts, and the introduction of new treatment devices. When disposing of equipment, it is recommended to report this to the Korea Institute of Nuclear Safety (KINS) and dispose of or store waste when considering the activation. In addition, discarding the linac after measurements have been taken and clearance is possible is recommended, although standards and procedures (e.g., clearance and consignment disposal) have yet to be established. In this study, to establish a basis for safety management procedures and regulations when replacing or discarding a medical linac, we analyzed current practices for managing radioactive waste from medical linacs in Korea and other countries.

\section{Status of Medical Linac Radioactive Waste Management in Korea}

\section{Status of medical linacs in Korea}

There are 103 hospitals using a linac in Korea, with a total of 182 linacs installed. Fig. 1 shows the number of linacs

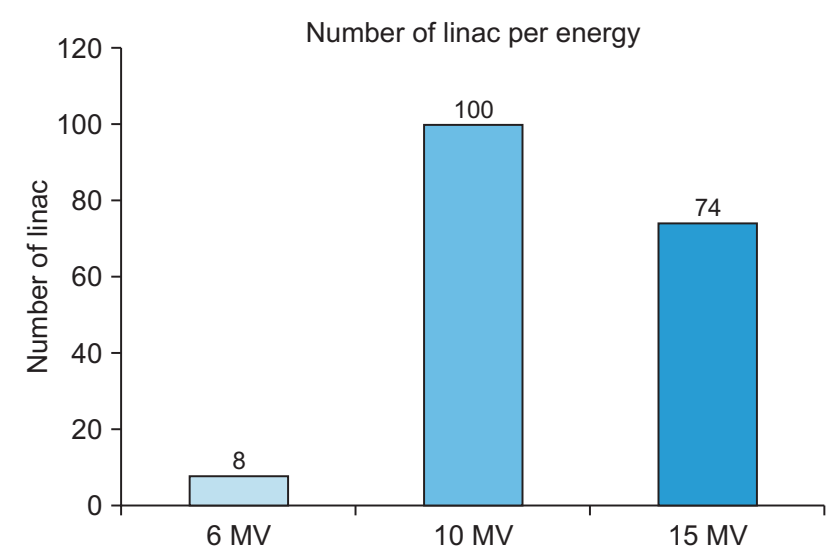

Fig. 2. Number of linear accelerators (linacs) by energy (19922020). 
according to the year they were installed from 1992 to 2020. A total of 66 linacs were installed between 1992 and 2010. Considering that the average life of a linac is 10 to 15 years, it is expected that their replacement or disposal owing to new installations will rapidly increase.

Fig. 2 shows an analysis of the energy used by installed linac equipment. Approximately 95\% of linacs use more than 10-15 MV of energy and more than 95\% of linacs use this energy to generate an activation product.

\section{Current state of disposal of medical linacs in Korea}

In Korea, no legally stipulated procedures or standards exist for linac disposal and thus disposal methods vary in different hospitals. The Nuclear Safety and Security Commission of Korea and the Korea Radioactive Waste Agency create regulations for the disposal of radioactive materials, such as radioisotopes.

Some hospitals store the entire head part of the radioactive linac in a radioactive waste storage facility at the hospital after detachment. In addition, several parts are used as education-assistive tools or are collected by replacement companies without evaluation of the radioactive concentration/contamination when replaced.

Some hospitals have applied a clearance or consignment disposal process by hiring a disposal company. The related disposal procedures are shown in Fig. 3, which shows that after shutdown of a linac, the equipment should be dismantled immediately or within one to two months after shutdown. When the linac is disposed, the disposal company measures the surface dose rate for each component by using a survey meter. When relocating or disposing of equipment through a company, these processes proceed without measuring the dose rate. Waste with a dose rate below the level of the background level of the dose rate (radiation) is disposed of as general waste and waste above the background is stored in the radioisotope waste storage facility of the hospital.

Currently, when disposing of a medical linac with a disposal company in Korea, a document on measures for disposing of a radiation-generating device is provided, as shown in Fig. 4. The document includes information on the disposal equipment, removal date, measures taken, results of the dose rate measurement, information on the detector used, and the calibration date. In addition, as shown on the Fig. $4 \mathrm{~b}$, the dose rate is measured using a survey meter for each component of the discarded linac. When dismantling, the surface dose is measured and recorded for each major component and reported to the KINS.

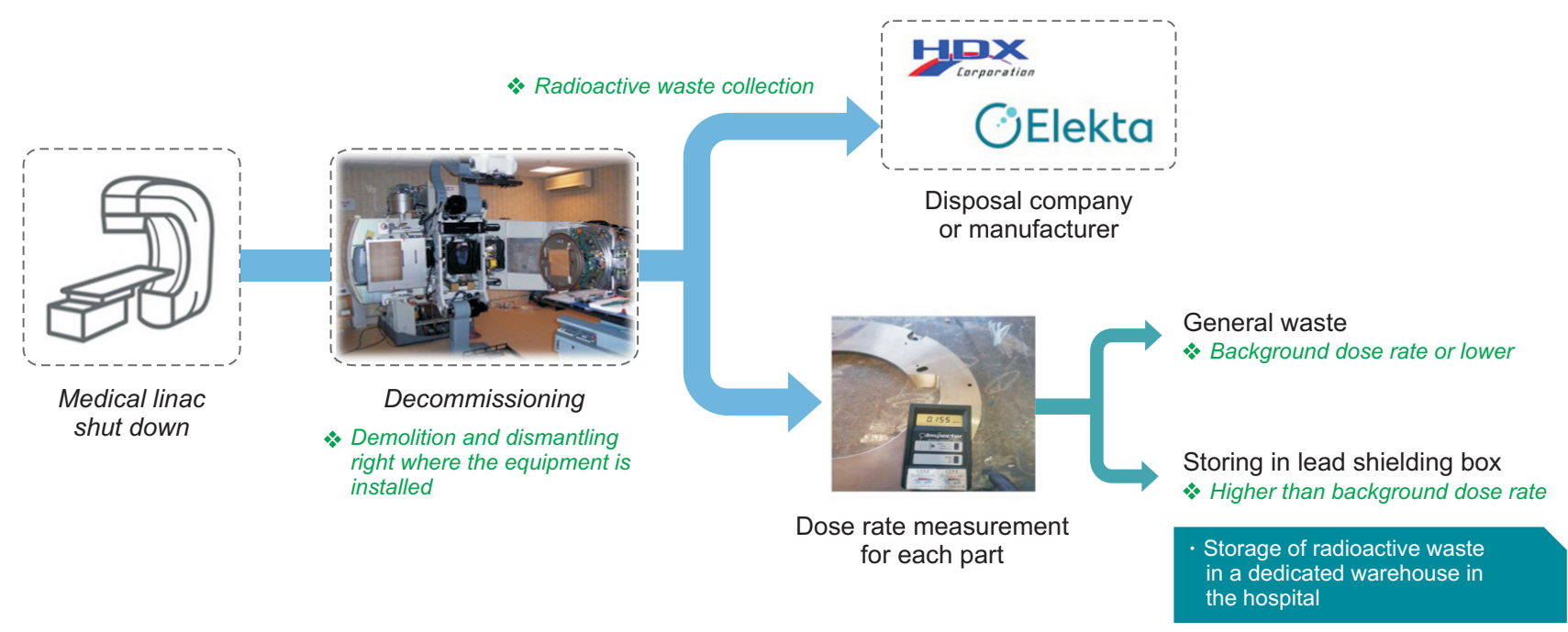

Fig. 3. Linear accelerator (linac) disposal and disposal procedure in Korea. 


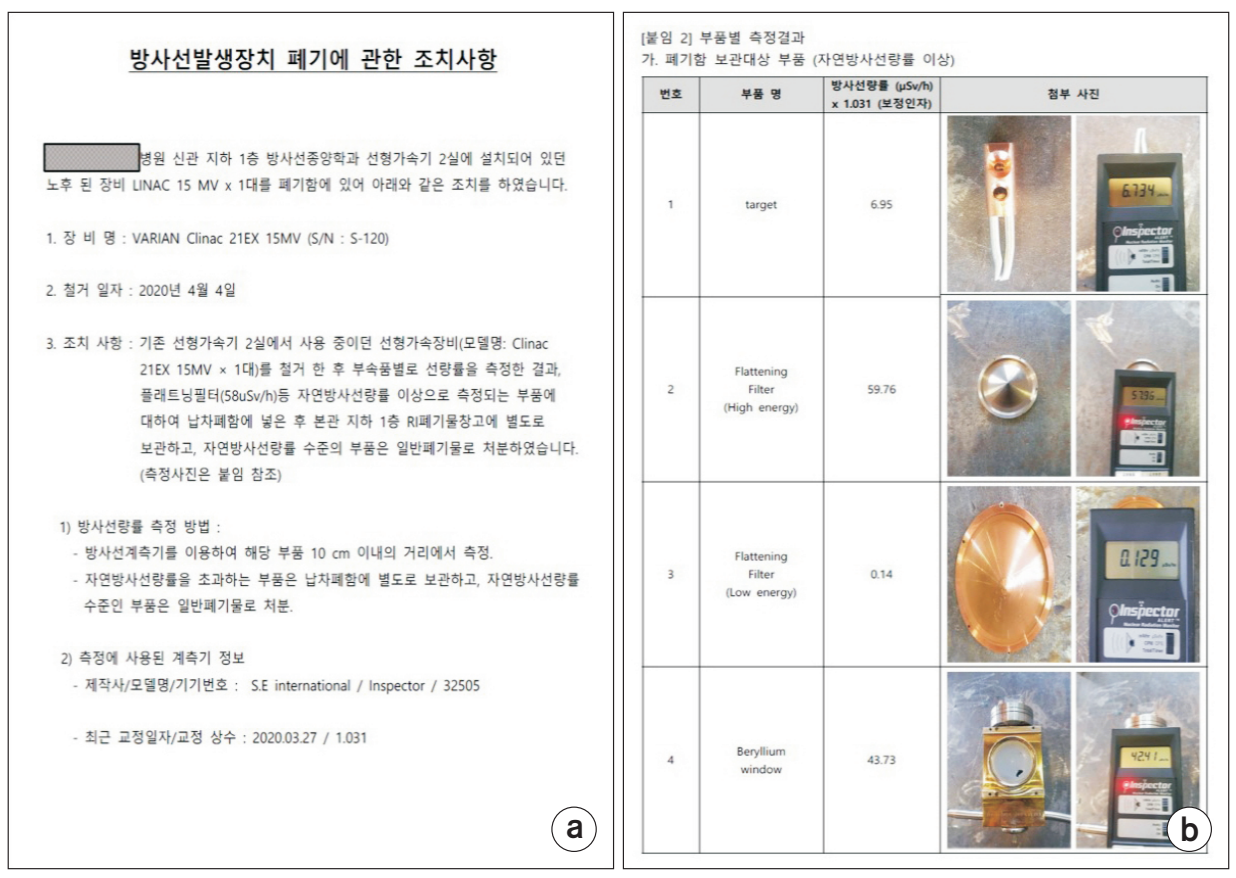

Fig. 4. Documents for measuring the disposal of radiation-generating device (a) and measurement of dose rate by parts of medical linac (b).

Table 1. Contents of general program documents and documents related to clearance

General program documentation

Related regulations and standards

Clearance and release/dismantling programs

Accelerator and facility parameters and operating history

Surface and volume radioactivity evaluation

Procedures and records of radiation area classification, measurement method, and location

Criteria for clearance

A description of the concept and measurement of proxy radionuclides and difficult to measure nuclides

Clearance measurement procedure for proxy radionuclides

Limits of detection for proxy radionuclides

Procedures and records for instrument calibration and testing

Procedures and records of training and qualifications for conducting measurements and using the device

Procedures and records for storage locations on site before release Plan for discussion with stakeholder
Additional documents for clearance

Additional process knowledge used in the measurement process during clearance (beam parameters and operating conditions, materials, etc.)

Records of past measurement of parts to be ejected

Description of facility and component

Radiation irradiation report: measurement conditions and results, including date and place of measurement, model and serial number of the detector, calibration date, background dose rate, inspection report, and measurement conditions and results

\section{Radioactive Waste Management Status of Medical Linacs in Other Countries}

\section{Status of linac radioactive waste management in the United States}

\section{1) Management of radioactive waste}

The US Department of Energy (DOE) published technical standards in 2016 to support the control, clearance, and release of personal property (materials, equipment, and items) from an accelerator, accelerator facilities, and modules. In this report, based on DOE Directive Order 458.1 and ANSI N13.12-2013, regulations regarding the requirements for radiological protection of the air and environment are described [6-8]. The DOE report is based on large accelerators, such as the SLAC (Stanford Linear Accelerator Center), and suggests clearance standards, process knowledge, and measurement methodology.

The total effective dose limit is set at $0.01 \mathrm{mSv} / \mathrm{y}$ for the disposal of properties with residual radioactivity as stipu- 
lated in O 458.1 and 10 CFR Part 835.1101. The DOE report presented the screening level and dose limit for surface and volumetric activity based on $0.01 \mathrm{mSv} / \mathrm{y}$ [9].

The DOE report recommends that process knowledge is used to determine whether radioactivity remains in the various parts of a linac during disposal. Process knowledge indicates whether a substance can be radiated or contaminated and classified as general knowledge or specific knowledge. General process knowledge includes information that is equally applicable to most accelerator installations with similar properties or operations, such as beam energy and particle types.

When disposing of a linac, a document should be produced that contains the contents of its work history, procedures, and measurements, including process knowledge, as shown in Table 1.

\section{2) Linac decommissioning and disassembly procedure}

Fig. 5 shows the linac disposal process [10]. After the linac is turned off, the head part is detached and its multileaf collimator (MLC), collimator head, gantry head, and bending magnet are discarded. Because the degree of activation varies according to the energy used in the linac, the parts must be disassembled and handled only after the recommended length of time. Components should not be removed until the dose rate is less than $50 \mu \mathrm{Sv} / \mathrm{h}(5 \mathrm{mrem} / \mathrm{h})$ at a distance of $1 \mathrm{ft}(30 \mathrm{~cm})$ from the surface of the linac.

- Accelerators using 10-14 MV X-ray energy: at least 1 hour after beam shutdown

- Accelerators operating above 15 MV X-ray energy: a longer attenuation period is recommended, typically 12-24 hours after beam shutdown

The list of hazardous substances and substances that should be removed from the linac gantry head, including non-radioactive parts, is as follows:

- Sealed components containing oil that may contain printed circuit boards (PCBs) (e.g., capacitors, transformers)

- PCBs with a surface area of $10 \mathrm{~cm}^{2}$ or larger

- Plastic containing brominated flame retardant

- External electric cable

- Ingredients containing radioactive substances

- Electrolytic capacitors containing substances of concern (height $\geq 25 \mathrm{~mm}$, diameter $\geq 25 \mathrm{~mm}$ )

- Beryllium (bending magnet beam exit window)

- Radiation shielding lead (bending magnet, collimator, carousel) and lead solder

- Metal surfaces, sheet metal, and hardware surfaces

\section{Status of linac radioactive waste management in Japan}

Regulations for the dismantling and disposal of radioactive waste are outlined in the Act on the Regulation of Radioactive Isotopes (Atomic Energy Regulatory Authority), the Medical Law/Medical Law Enforcement Rules (Ministry

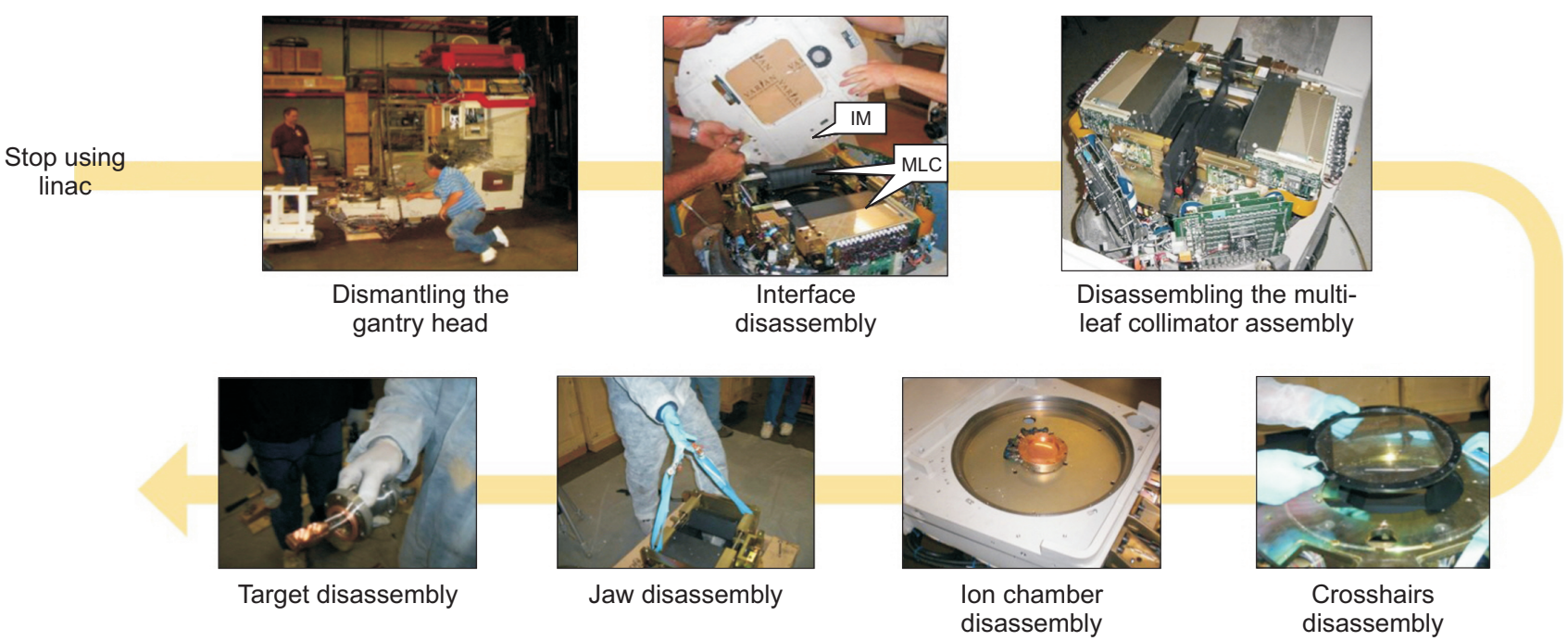

Fig. 5. Medical linear accelator (linac) disassembly and disassembly procedure. IM, Interface Mount; MLC, multileaf collimator. 
of Health, Labor, and Welfare), the Labor Safety and Sanitation Act, and the Radio Law (Ministry of Internal Affairs and Communications). In Japan, regulations and facility standards, such as storage, disposal, incineration, and disposal of radioactive waste, are applied in the same manner as applied to waste contaminated by radioisotopes [11].

\section{1) Procedure for replacement and abolition}

The procedures followed during the preparation stage for replacement of equipment or abolition of the facility is shown in Fig. 6. Japan recommends forming a dedicated group to replace equipment, as well as an additional review group within an institution that uses a linac. The institution that uses the linac investigates the status of the
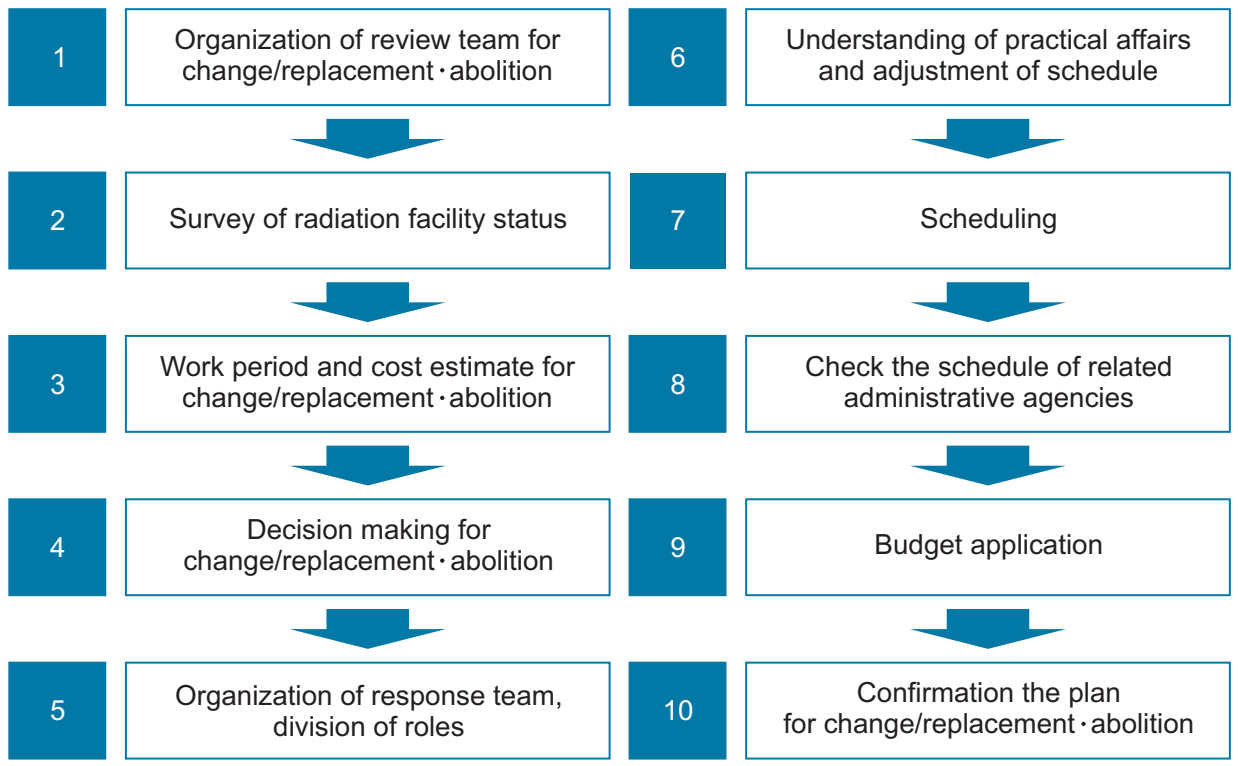

Fig. 6. Linear accelator (linac) dismantling and component disposal process in Japan.

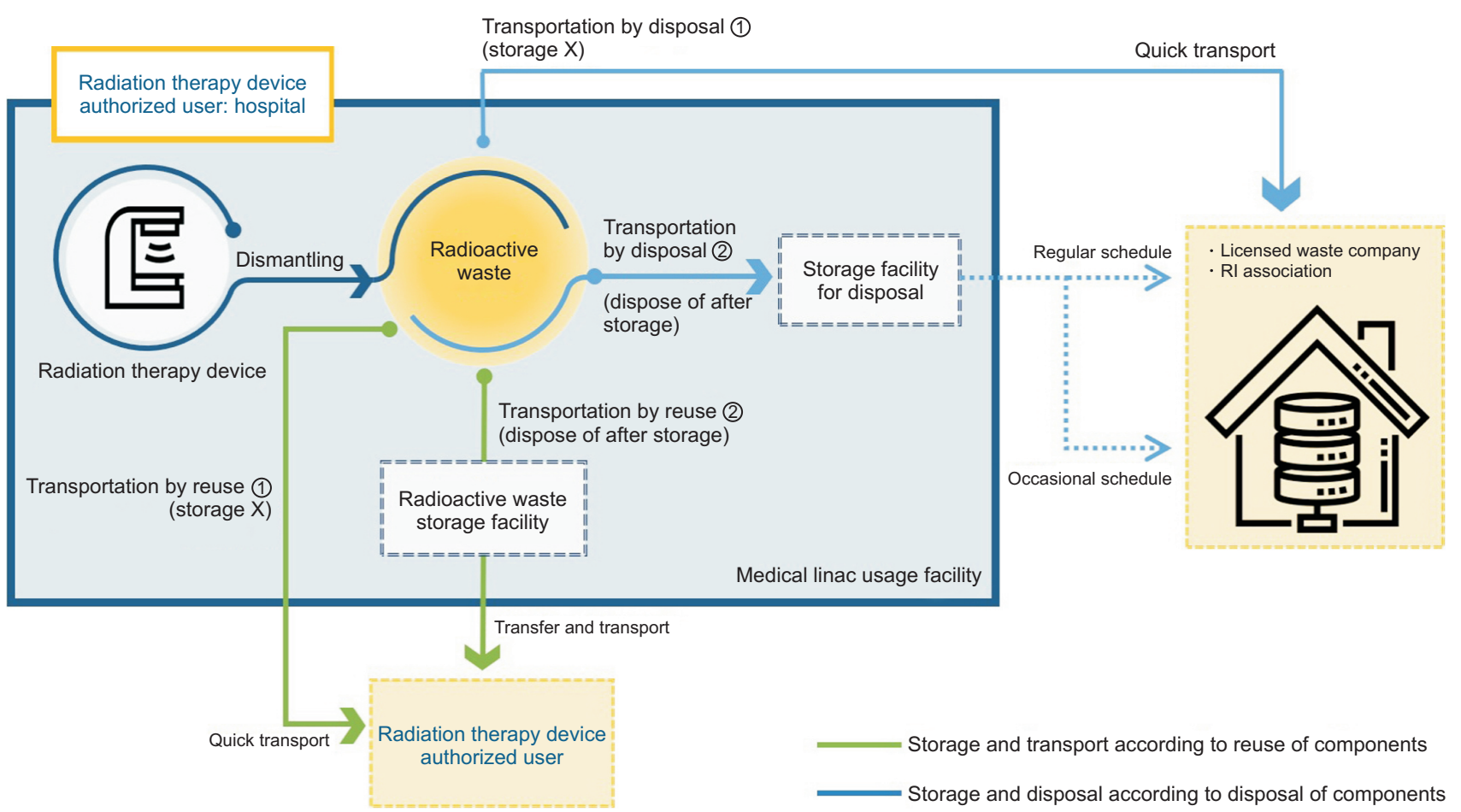

Fig. 7. Process of reuse and disposal of radioactive waste for radiation therapy device. Linac, linear accelator; RI, radiation isotope. 
facility and conducts an overall estimate of the work to be performed and the cost. Next, a procedure for finalizing a disposal plan should be created by making decisions on institutional policies, the division of roles, scheduling, and budget.

When replacing or disposing of equipment, the user should classify and dismantle the radioactive components (regulated parts). In addition, the components are divided into those that can be reused and those to be disposed of, as shown in Fig. 7. Equipment to be reused is transported to a licensed user at another facility. Transportation immediately after dismantling or storage in a radioactive waste storage facility are optional. Equipment to be discarded is either immediately disposed of without first storing it in a storage disposal facility or it is stored similarly to equipment that is reused.

\section{2) Measurement procedure for activation}

The procedure for radiation measurement during disassembly of a linac is shown in Fig. 8. Radiation measurements related to the handling of radioactive waste should be conducted when disposing of regulated activation products, for products to be taken out of the radiation-controlled area, and for transport. The dose rate is measured at a distance of $1 \mathrm{~cm}$ from the equipment part by using a survey meter and the dose rate is converted into Bq according to the conversion table used in Japan. After determining the reference dose of the radionuclides, the components are divided and stored in a drum.

In addition, if storage and disposal facilities are installed, periodic dose measurements are required. The types of measurements are divided into cases that the medical institution directly conducts and cases that are entrusted to a professional contractor. In addition, the final evaluation should be conducted by the medical institution even in the case of consignment.

\section{Status of linac radioactive waste management in Europe}

The European Commission provides recommendations on the "Practical use of the concepts of clearance and exemption" in accordance with the Radiation Protection
Report 122 as published in 2000 [12]. In principle, waste should not be generated and resources should be reused; however, radioactive materials are classified as exceptions and disposal is recommended.

In the case of radioactive waste, it is not necessary to report radioactive material with an activity concentration below the specific exemption for nuclides and prior approval for disposal is not required. The standard for clearance of radioactive waste is $10 \mu \mathrm{Sv} / \mathrm{y}$ for individuals and $1 \mathrm{man}-\mathrm{Sv} / \mathrm{y}$ for collective doses. The standards for clearance follow the IAEA Safety Series 89, but the Commission has difficulty linking dose standards for authorization and disposal with

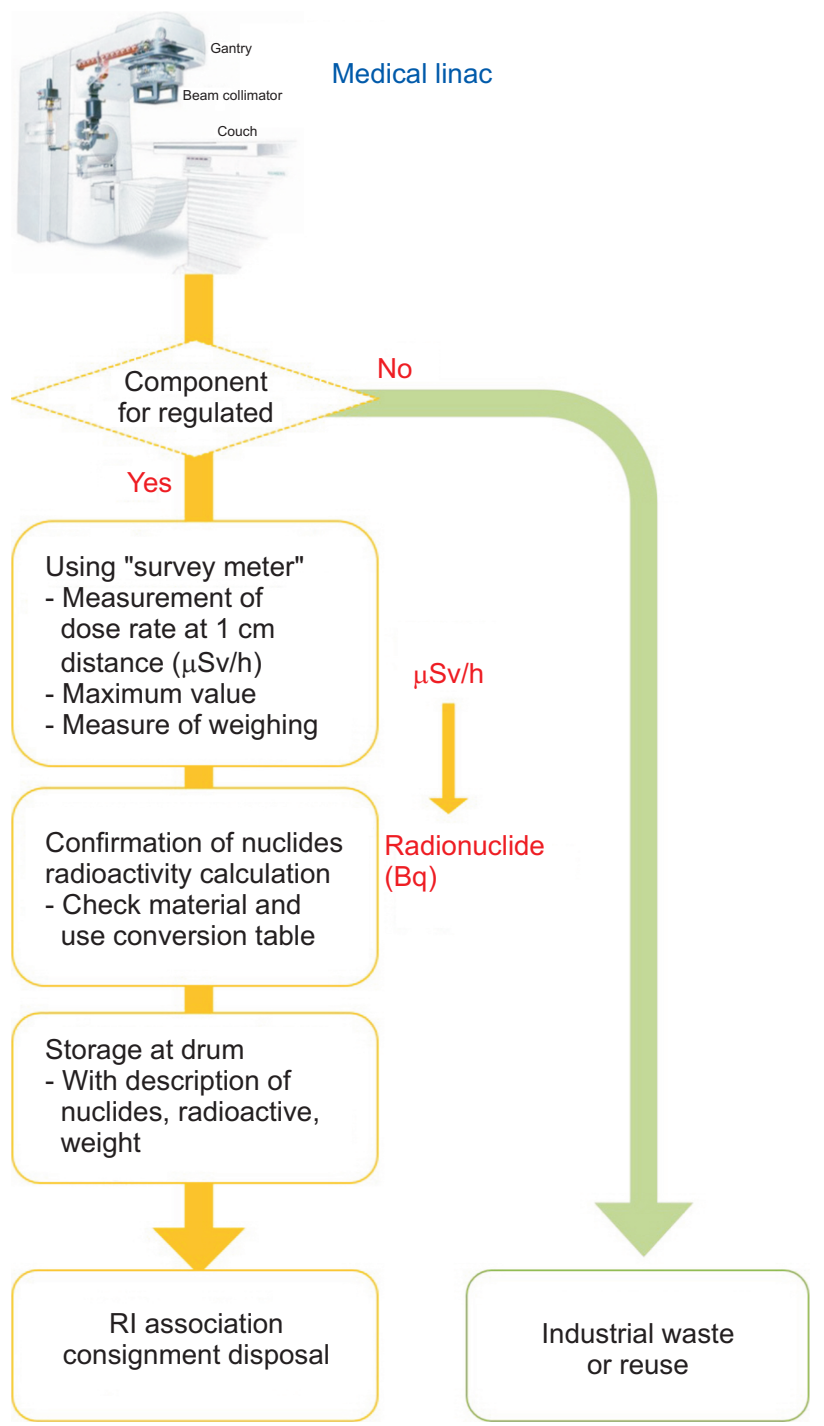

Fig. 8. Measurement and disposal of radioactive waste for medical linear accelerator (linac). RI, radiation isotope. 
individual exposure. Therefore, exposure scenarios are typically constructed to obtain individual doses [13].

\section{1) Linac disposal management in Germany}

Germany's Radiation Protection Committee recommends clearance criteria for accelerators based on a report, "Clearance of accelerators and the removal of accelerator parts from radiation protection areas," which was published in 2009 [14]. Dismantling and disposal should be performed based on the history of an accelerator, operating time, and component materials. In particular, the establishment of a disposal standard for an accelerator is proposed by considering the nuclides of each component. However, as in Korea, no clear procedures and regulations exist, but these will be considered in the next revision of the radiation protection regulations.

In accordance with the treaty (2016/C 203/01) published in 2016 by the European Atomic Energy Community (Euratom), European Union (EU) countries, such as Germany, Sweden, the United Kingdom, and France, have prepared disposal plan reports for when radioactive waste is generated [15]. Each member state must provide the European Committee with a radioactive waste disposal plan and determine whether the implementation of the plan could result in water, soil, or radioactive contamination. The reports must include information about the facility from which the waste originated, the distance to the EU member state closest to the facility, whether the waste is stored prior to transportation, and whether it is within the dose limits [16].

\section{Status of linac radioactive waste management in Canada}

In Canada, to dismantle a facility where a medical linac is used, a permit application is first submitted, as well as a plan of action. As shown in Table 2, a final decommissioning report, including a decommissioning plan, information on generated radioactive materials, preparation for disposal of other hazardous substances, and other factors, should be prepared and submitted to the Canadian Nuclear Safety Commission (CNSC). At this time, Class II equipment is regulated as follows:

- Particle accelerators with beam energy of less than 50 $\mathrm{MeV}$ that are capable of producing nuclear energy

- Irradiators using nuclear material of 1,015 Bq or higher

- Irradiators requiring shielding because the dose rate at $1 \mathrm{~m}$ exceeds $1 \mathrm{cGy} / \mathrm{min}$

- External treatment devices or remote brachytherapy devices (afterloaders) using a radioactive source

1) Disposal method in Canada

Canada disposes of parts differently depending on the

Table 2. Content of final medical linear accelerator dismantling report in Canada

\begin{tabular}{|c|c|}
\hline $\begin{array}{l}\text { Outline of the decommissioning } \\
\text { plan }\end{array}$ & $\begin{array}{l}\text { Decommissioning schedule } \\
\text { Information on structures, components, systems, equipment, nuclear materials, and land that will be } \\
\text { affected by the dismantling } \\
\text { Problems that may arise from dismantling and proper measures } \\
\text { Whether pollutants, radioactive products, or other harmful substances remain after dismantling }\end{array}$ \\
\hline $\begin{array}{l}\text { Manpower qualification and } \\
\text { training }\end{array}$ & $\begin{array}{l}\text { Name and title of the person responsible for decommissioning plan } \\
\text { Qualifications and training requirements of workers } \\
\text { Dismantling of external facilities: name and information of the relevant institution, regardless of } \\
\text { whether safety education has been completed } \\
\text { Accelerator disassembly requires a license for Class II regulated equipment }\end{array}$ \\
\hline $\begin{array}{l}\text { Estimation of the type, activity, } \\
\text { and radiation dose of nuclear } \\
\text { materials }\end{array}$ & $\begin{array}{l}\text { The properties, types, and radioactivity of radioactive materials or contamination information of the } \\
\text { nuclear facility } \\
\text { Products and components expected to be radioactive upon dismantling } \\
\text { Estimates of radioactivity } \\
\text { Estimated maximum dose rates and doses that a person can be exposed to as a result of dismantling }\end{array}$ \\
\hline $\begin{array}{l}\text { Disposal of Class II regulated } \\
\text { equipment, nuclear and } \\
\text { hazardous materials }\end{array}$ & $\begin{array}{l}\text { Proposed final disposal method for the major components of the accelerator (e.g., sale or disposal, } \\
\text { return to the manufacturer, transfer to another facility for potential reuse, or kept by the license } \\
\text { holder for future reuse) } \\
\text { Transfer to another institution: recipient's name and contact information } \\
\text { Information on whether material is released into the environment and the maximum amount and } \\
\text { concentration of nuclear and hazardous substances that can be released }\end{array}$ \\
\hline
\end{tabular}


level of activation of products from medical linacs and the possession of a CNSC license. In the case of a permitted facility with a CNSC license, the linac is returned to its manufacturer. If the facility has no license, the accelerator or its components are transferred to a repair company. Except for the above examples, waste is typically disposed according to clearance criteria.

Other than for a return to the manufacturer (in the case of a transfer to a repair company) or when using general waste disposal methods, the requirements of section 5.1 of the Nuclear Substances and Radiation Device Regulations must be satisfied [17]. In the absence of a license, a linac can be disposed of if the radioactivity or concentration of radioactive nuclear material does not exceed standard guidelines. In Canada, a dose rate-based measurement method is recommended. In the case of medical accelerators, conditional clearance is allowed if the measurement is less than $0.5 \mu \mathrm{Sv} / \mathrm{h}$ when measured at $5 \mathrm{~cm}$ from the accessible surface of the component [18].

\section{Radioactive waste management and comparison of clearance level}

1) Comparison of storage management of radioactive waste

After disassembly of the linac, the classified radioactive parts must be stored in a storage box that conforms to a certain standard or disposed of after storage. In countries that recommend storage boxes for storing radioactive waste and linac parts, we classified the standards of Japan's Society Standard Technical Reports and reports from Varian Co., as shown in Table 3 [11]. The basic standard is 50 $\mathrm{L}$ in Japan and $210 \mathrm{~L}$ in the United States. In Japan, an application is submitted to borrow a waste storage container. A $50 \mathrm{~L}$ drum can be borrowed for free and $210 \mathrm{~L}$ drums are rented for a fee. At this time, four 50-L drums are typically used. In the United States, 55 gallon $(210 \mathrm{~L})$ drums and the insertion of foam are required for the storage and management of radioactive parts. It is recommended that

Table 3. Comparison of medical linac radioactive waste storage containers

\begin{tabular}{|c|c|c|}
\hline Country & Japan & USA \\
\hline Standard & $\begin{array}{l}50 \mathrm{~L} \\
\text { Inner diameter and height: } 33 \mathrm{~cm}, 55 \mathrm{~cm} \\
\text { Less than } 60 \mathrm{~kg} \text { per container }\end{array}$ & 210 L (55 gallons) \\
\hline Other information & $\begin{array}{l}\text { Fill out the application for borrowing of waste containers } \\
\text { Typically, four } 50 \text { - } \mathrm{L} \text { drums are required } \\
\text { Free rental of } 50 \mathrm{~L} \text { drums } \\
\text { If the parts are large, } 200 \mathrm{~L} \text { drum is used, but container } \\
\text { fee and container shipping fee are charged }\end{array}$ & $\begin{array}{l}210 \mathrm{~L} \text { drum and inserted foam are required as standard } \\
\text { for storage and maintenance of radioactive components } \\
\text { For storage of other parts, capacitors, etc.: three 19-L } \\
\text { steel drums } \\
\text { Two plastic tarpaulins for floor protection and } \\
\text { contaminated dust collection } \\
\text { Wooden pallet }\end{array}$ \\
\hline
\end{tabular}

Table 4. Criteria for evaluation and clearance of radioactive waste in the linac

\begin{tabular}{|c|c|c|c|}
\hline Country & Japan & USA & Canada \\
\hline $\begin{array}{l}\text { Measuring } \\
\text { instrument }\end{array}$ & $\mathrm{NaI}(\mathrm{Tl})$ scintillation survey meter & $\begin{array}{l}\text { NaI(Tl) scintillation survey meter, Geiger- } \\
\text { Muller (GM) counter Counter, etc. }\end{array}$ & Survey meter \\
\hline $\begin{array}{c}\text { Measuring } \\
\text { location }\end{array}$ & $1 \mathrm{~cm}$ distance & $1 \mathrm{~cm}$ distance & $5 \mathrm{~cm}$ distance \\
\hline $\begin{array}{l}\text { Clearance } \\
\text { criteria }\end{array}$ & $10 \mu \mathrm{Sv} / \mathrm{y}$ & $10 \mu \mathrm{Sv} / \mathrm{y}(1 \mathrm{mrem} / \mathrm{y})$ & $0.5 \mu \mathrm{Sv} / \mathrm{h}(10 \mu \mathrm{Sv} / \mathrm{y})$ \\
\hline Other & $\begin{array}{l}\text { Calculate the amount of radioactivity } \\
(\mathrm{Bq}) \text { based on the dose rate }(\mu \mathrm{Sv} / \mathrm{h}) \\
\text { measured (weight measurement and } \\
\text { conversion factor applied) }\end{array}$ & $\begin{array}{l}\text { Effective distance of scintillator } \\
\text { instrument: } 1 \mathrm{~cm} \text { from the surface } \\
\text { [SLAC Accelerator] When metal/concrete } \\
\text { is irradiated at a volume radiation level } \\
\text { of } 1 \mathrm{pCi} / \mathrm{g} \rightarrow \sim 1 \mathrm{mrem} / \mathrm{h} \text { at a distance of } \\
2 \mathrm{~cm} \text { from the surface }\end{array}$ & $\begin{array}{l}\text { When converting to the effective dose, } \\
\text { use the } 30 \mathrm{~cm} \text { standard (distance } \\
\text { inverse square law) } \\
\text { Calculated assuming an average } \\
\text { working time of } 40 \text { hours and that } 15 \\
\text { linac parts are managed per year }\end{array}$ \\
\hline
\end{tabular}

SLAC, Stanford Linear Accelerator Center. 
three 5-gallon (19 L) steel drums are used for other parts and that two plastic tarps are used to protect the floor and collect contaminated dust. Wooden pallets can be used if necessary.

2) Comparison of radioactive waste disposal standards and radioactive evaluation methods of medical linacs

The clearance criteria for radioactive waste from the medical linac and the method of evaluating the activation differ, as shown in Table 4. As a detector for evaluating radioactive waste, Japan, the United States, and Canada typically use a survey meter. The location of the measurement is at a distance of $1 \mathrm{~cm}$ in Japan and the United States, but $5 \mathrm{~cm}$ in Canada. The clearance criterion is $10 \mu \mathrm{Sv} / \mathrm{y}$ in all three countries, which is the same as in Korea. Canada allows a clearance of $0.5 \mu \mathrm{Sv} / \mathrm{h}$ or less. This is a calculated value assuming that the annual allowance standard is an average working time of 40 hours and that 15 linac parts are managed per year.

\section{Conclusions}

In this study, to establish safety regulation guidelines and procedures for the management of radioactive waste from medical linacs in Korea, the current management practices in Korea and abroad were investigated.

As a result of this investigation, it was shown that standards and procedures for disposing of a linac have yet to be established in Korea. Because activated waste generated by a medical linac is not classified as radioactive waste, the Korean radioactive waste agency, a facility that disposes and manages waste, handles only radioisotopes.

Because no legally prescribed procedure or standard for disposing of a linac exists, it was found that most medical institutions do not have safety management regulations. In addition, radioactive waste is collected by companies without following any procedures or guidelines or the head of medical linacs are stored in the waste storage areas at hospitals. It was shown that the institutions or individual owners in Korea collect the waste by using a company but without any action taken at medical institutions.

Japan, the United States, and Canada have guidelines to treat radioactive waste that is produced by a linac. Japan has regulated radioactive cargo from linacs in the same way that radioactive isotopes are regulated, and the United States and Canada have proposed clearance criteria for radioactive waste. However, most reports from the EU, the International Atomic Energy Agency, and the United States have provided management guidelines for research or large-scale accelerators, but not for linacs.

For the safe management of a medical linac, it is necessary to establish safety management regulations for radioactive waste produced at medical institutions.

First, before dismantling the linac, a dismantling and disposal plan must be prepared and reported to the KINS as recommended by European nations, such as Germany. In addition, medical institutions should form a dedicated team that will perform the work, as is done to Japan. For the process of disposal, as suggested by the processes performed Japan, the United States, and Canada, the dose rate of the components is measured using a survey meter and the general and radioactive waste should be classified according to the $0.5 \mu \mathrm{Sv} / \mathrm{h}$ standard. In addition, the sorted parts must be stored or transported in standardized drums 50 or $210 \mathrm{~L}$ in size.

In Korea, standards for disposal, such as dose limits, are required for medical linacs. As in other countries, a system for the disposal of a linac according to a clear procedure should be established.

\section{Acknowledgements}

This work was supported by the Nuclear Safety Research Program through the Korea Foundation of Nuclear Safety (KoFONS) using the financial resources granted by the Nuclear Safety and Security Commission (NSSC) of the Republic of Korea (No. 2003013).

\section{Conflicts of Interest}

The authors have nothing to disclose.

\section{Availability of Data and Materials}

All relevant data are within the paper and its Supporting Information files. 


\section{Author Contributions}

Conceptualization: Na Hye Kwon, Sang Hyoun Choi. Data curation: Na Hye Kwon. Funding acquisition: Sang Hyoun Choi. Investigation: Jin Sung Kim. Methodology: Kum Bae Kim, Dong Wook Kim. Project administration: Sang Hyoun Choi. Validation: Dong Oh Shin. Visualization: Young Jae Jang. Writing-original draft: Na Hye Kwon. Writing-review \& editing: Nahye Kwon, Sang Hyoun Choi.

\section{References}

1. International Atomic Energy Agency. Management of radioactive waste from the use of radionuclides in medicine. Vienna: International Atomic Energy Agency. 2000; IAEATECDOC 1183.

2. National Council on Radiation Protection and Measurement. Neutron contamination from medical electron accelerators. Washington, DC: National Council on Radiation Protection and Measurement. 1984; NCRP Report No. 79.

3. National Council on Radiation Protection and Measurement. Structural shielding design and evaluation for megavoltage $\mathrm{X}$ - and gamma-ray radiotherapy facilities. Washington, DC: National Council on Radiation Protection and Measurement. 2005; NCRP Report No. 151.

4. Lee J, Kim H, Kim M, Song M, Cho D, Yoon H, et al. Management plan for radioactive waste generated when dismantling the medical linear accelerator. Paper presented at: Workshop for Improving Safety Management in Medical Field; 2017 Nov 22-24. p. 408-409.

5. Nuclear Safety and Security Commission Notice 2017-65. Regulations on radioactive waste classification and clearance standards. Sejong: Radioactive Waste Safety Division, Nuclear Safety and Security Commission; 2017.

6. Health Physics Society. Surface and volume radioactivity standards for clearance. McLean: Health Physics Society. 2013; ANSI N13.12.

7. U.S. Department of Energy. Clearance and release of personal property from accelerator facilities. Washington, DC:
U.S. Department of Energy. 2016; DOE-STD-6004-2016.

8. U.S. Department of Energy. Radiation protection of the public and the environment. Washington, DC: U.S. Department of Energy. 2013; DOE O 458.1.

9. U.S. Department of Energy. Occupational radiation protection program. Washington, DC: U.S. Department of Energy. 2011; CFR 835.

10. Varian Medical Systems. HE clinic Gantry Head Hazardous Substances and Material Removal and Disposal. Palo Alto: Varian Medical Systems, Inc.; 2014.

11. Japanese Society of Radiation Oncology. Society standard for the management of radioactive substances in radiotherapy equipment. Japanese Society of Radiation Oncology; 2014.

12. European Commission. Practical use of the concepts of clearance and exemption- part 1. European Commission. 2000; Radiation protection 122.

13. International Atomic Energy Agency. Principles for the exemption of radiation sources and practices from regulatory control. Vienna: International Atomic Energy Agency. 1988; IAEA 89.

14. Strahlenschutzkommission. Clearance of accelerators and the removal of accelerator parts from radiation protection areas. Strahlenschutzkommission; 2009.

15. European Union. Official Journal of the European Union. Consolidated version of the Treaty establishing the European Atomic Energy Community. European Union. 2016; 2016/C 203/01.

16. European Union. Official Journal of the European Union. Relating to the plan for the disposal of radioactive waste arising from the European Spallation Source Facility (Linear Accelerator). European Union. 2015; 2015/C 72/01.

17. Canadian Nuclear Safety Commission. Nuclear substances and radiation devices regulations. Ottawa: Canadian Nuclear Safety Commission. 2015; 2000-207.

18. Canadian Nuclear Safety Commission. Conditional clearance levels for the disposal, recycling and reuse of activated medical accelerator components. Ottawa: Canadian Nuclear Safety Commission; 2018. 